\title{
The impact of patients' chronic disease on family quality of life: an experience from 26 specialties
}

This article was published in the following Dove Press journal:

International Journal of General Medicine

17 September 2013

Number of times this article has been viewed

\author{
Catherine Jane Golics' \\ Mohammad Khurshid \\ Azam Basra ${ }^{2}$ \\ M Sam Salek' \\ Andrew Yule Finlay ${ }^{2}$ \\ 'Centre for Socioeconomic \\ Research, School of Pharmacy and \\ Pharmaceutical Sciences, ${ }^{2}$ Department \\ of Dermatology and Wound Healing, \\ Cardiff University School of Medicine, \\ Cardiff University, Cardiff, UK
}

Background: Previous studies have assessed family quality of life in individual disease areas and specialties. The aim of this study was to investigate the impact of disease on family members of patients over a wide range of specialties and identify key impact areas. This information is essential in order to reveal the extent of this impact and to allow strategies to be developed to support the family members of patients with chronic disease.

Methods: Semi-structured interviews were carried out with 133 family members of mostly chronically ill patients from 26 medical specialties. Family members were invited to discuss all areas of their lives that had been affected by having an unwell relative. Thematic analysis was carried out using NVivo9 ${ }^{\circledR}$ software.

Results: Most family members were female (61\%), the partner or spouse of the patient $(56 \%)$, or the parent (22\%). Their mean age was 56.1 years (range: $21-85$ years) and the mean duration of the patient's disease was 8.9 years (range: 1 month to 60 years). Ten key themes of family quality of life were identified from interviews. The median number of themes reported by family members was six (range: $1-10$ ). The key themes included: emotional impact (mentioned by $92 \%$ of subjects), daily activities (91\%), family relationships (69\%), sleep and health (67\%), holidays $(62 \%)$, involvement in medical care and support given to family members $(61 \%)$, work and study (52\%), financial impact (51\%), social life (37\%), and time planning (14\%). Relationships between the themes were identified.

Conclusion: This large scale multi-specialty study has demonstrated the significant, yet similar, impact that illness can have on the quality of life of patients' family members. Family quality of life is a previously neglected area of health care which needs to be addressed in order to provide appropriate support for the patient and the family unit.

Keywords: greater patient, secondary impact of disease, emotional impact, financial impact, social impact, family activities

\section{Background}

The quality of life of family members, ${ }^{1}$ as well as of patients, ${ }^{2}$ can be hugely reduced in terms of physical effects, psychological distress, and social problems. In dermatology, family members of patients experience emotions such as worry, frustration, and stress. ${ }^{1}$ Parents of children with physical and mental disabilities experience social problems, ${ }^{3}$ and the work life of family members of cancer patients is affected. ${ }^{4}$ Previous work has shown that family members of patients can be more emotionally affected by illness than patients themselves. ${ }^{5,6}$

It is unknown whether the issues affecting family members of patients are unique to those with specific diseases or whether family members are impacted in similar ways regardless of the patient's condition. The quality of life of family members
Correspondence: Catherine Jane Golics Centre for Socioeconomic Research, School of Pharmacy and Pharmaceutical Sciences, Cardiff University, Redwood Building King Edward VII Avenue CFI0 3NB, Cardiff, UK

Tel +44292087 60I7

Fax +442920874535

Email catherinegolics@hotmail.com 
of patients is important to understand so that appropriate strategies can be developed to meet their needs. These family members are often critical to successful patient care, ${ }^{7}$ and it is therefore important that they are provided with relevant support services. At present, the only literature exploring the impact of illness on family members of patients exists in individual specialties, and there is no literature available to inform the content of generic family support groups. Much of the existing work regarding family members focuses on family caregivers, often overlooking those who may not identify themselves as carers but live with or spend time with the patient and may still be greatly affected. This study is unique in that it focuses on family members in general, rather than carers.

It seemed likely that the types of impacts on other family members of having a person in a family with a chronic disease would be similar across many chronic diseases. In other words, having a chronic disease itself, rather than the type of chronic disease, would have common impacts on the lives of other family members. The common areas that might be similarly affected, whatever the specific diagnosis, include emotional impact, financial aspects, social life, time commitments, personal relationships, and family activities such as family holidays (vacations). This has not been previously systematically examined but it was considered important to do so because by identifying which common themes do exist, it would then be possible to develop generic support services for family members of patients with chronic disease.

The aim of this study was to explore the impact of disease on family members of patients with chronic conditions over a wide range of areas of medical practice and to identify the key impact areas.

\section{Methods}

\section{Sample}

Between five and six family members were selected from different medical and surgical specialties (Table 1). Specialties branches or fields of medicine or surgery - were selected to represent a wide variety of diseases. Patients from the specialty "mental health" suffered from common illnesses such as depression and anxiety. There is often comorbidity with mental health disorders occurring in parallel with other chronic diseases. It was therefore important that family members of patients with mental health disorders were included in the study. Patients from primary care (general practice) were also recruited. In the UK, this is considered a separate medical specialty. Patients and family members were recruited during visits to the doctor, during ward visiting hours, or at home. Using a purposive
Table I The 26 specialties included in the study (number of family members recruited from each specialty)

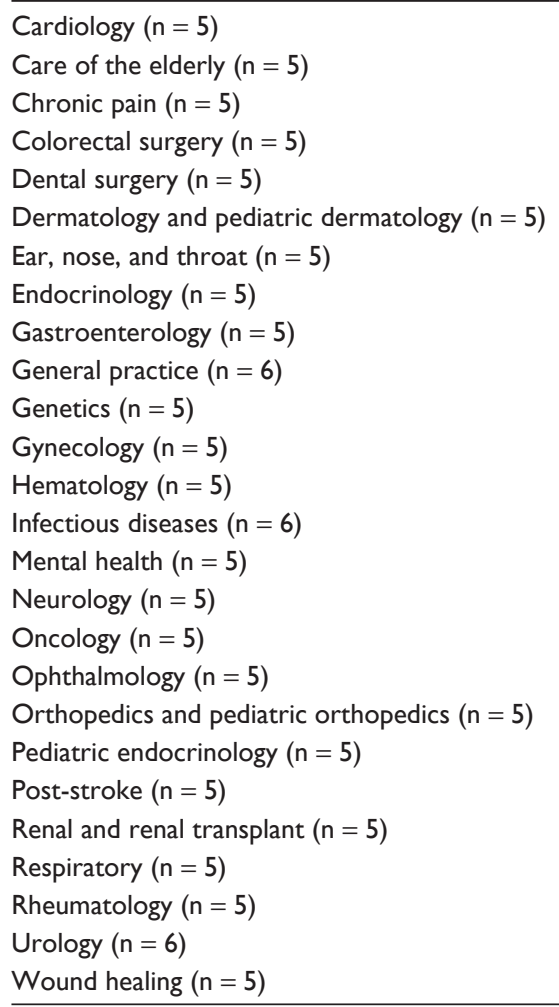

sampling method, adult and child patients were selected with the help of a senior specialist from each specialty and with a range of conditions which best represented their specialty. The accompanying family member of each patient was then approached to be interviewed by a senior specialist in nearly all cases, or occasionally by the researcher. During clinics, patients and family members were approached in person as they arrived at the appointment. Purposive sampling was used, ie, patients with a range of conditions from each specialty were selected rather than using random sampling which may not have resulted in a diverse sample, as only five patients were being selected in each specialty. This is a type of sampling method mostly used in qualitative research in which the sample is selected based on the knowledge of a population and the purpose of the study. The subjects are selected because of some characteristic based on research aims.

Participants were eligible if $>18$ years old, a family member or partner of a patient, and able to read and understand English. Family members of patients with comorbidities were also eligible. Only one member of each family was interviewed during the study. There were no exclusion criteria. In this qualitative study, the authors did not want to overlook any themes or impacts. Therefore, no exclusion criteria were specified as to do so may have resulted in missing some themes, eg, 
those related to condition or age of patient or family member. Written informed consent was given by both the patient and the family member before the interview.

Interviews took place in Cardiff, UK at the University Hospital of Wales $(n=77)$, University Hospital Llandough $(\mathrm{n}=40)$, Gabalfa Clinic $(\mathrm{n}=1)$, Velindre Cancer Centre $(\mathrm{n}=5)$, in general practice $(n=6)$, or at the participant's home $(n=4)$. Interviews were carried out in a private room without the patient present, except when the patient was $<10$ years old.

\section{Data collection}

The use of semi-structured interviews was selected to encourage the family members to talk widely and openly, ${ }^{8}$ and allowed for the discussion of sensitive and emotional issues. Qualitative interviews with family members of patients with a wide variety of medical conditions (varying in duration, type, and severity) were carried out, all by the same interviewer (CJG). An open style of questioning was used and participants were encouraged to give examples. The interview guide was developed from previous disease-specific studies and based on the research team's experience in the field, contained 25 questions, and used an opening style of questioning (summary in Supplementary materials). The opening interview question was "Can you tell me about any ways your life has been affected by your family member's illness?" Once these had been discussed in detail, the interviewer asked about other areas of the participant's life that could have been affected, as informed by the previous disease-specific literature. Five pilot interviews were carried out before the interviews began. The study team then met to discuss whether any changes to the interview guide or procedure were needed. The five pilot interviews proved successful and nothing was changed as a result. The pilot interviews were not included in analysis. The saturation point for the interviews was noted (the interview number where after no new themes arise), although interviews were continued until at least five family members had been sampled from each of the 26 specialties, in case new themes were identified from the specialties sampled in the later part of the study. This approach is recommended by Kerr et al, ${ }^{9}$ who suggest that there is little point in assessing saturation point until the full diversity of patient characteristics has been represented.

\section{Thematic analysis}

Demographic information was recorded about the patient and family member. All interviews were audio recorded with consent and transcribed verbatim. Data were analyzed using PASW $^{\circledR}$ Statistics 18 (for quantitative descriptors; SPSS Inc., Chicago, IL, USA) and NVivo $9^{\circledR}$ (qualitative data analysis software; QRS International, Doncaster, Australia). The process of coding the data included familiarizing oneself with the data, generating initial codes, searching for themes, reviewing themes, and then defining and naming themes. ${ }^{10}$ In many quality of life studies, coding frames are developed based on the content of the interviews before coding begins. ${ }^{11}$ It was felt that as this area of research had not been explored previously, a rigid coding frame would be too restrictive. Instead, before coding began, the interviewer identified ten main themes from the content of the transcripts and these themes were used as a starting point for coding. The study team then met to discuss the naming and interpretation of each of the themes before coding began. The coding was carried out after all 133 interviews had been completed, to ensure that family members from all specialties were represented in the study. The coding process was repeated twice by the interviewer using the NVivo software, repeated manually by the interviewer, and the coding and themes identified were discussed in detail with the study team at all stages. Figure 1 contains a flow diagram of the analytical process.

\section{Ethical considerations}

Approval was granted by the South East Wales Research Ethics Committee and the Research and Development department of the Cardiff and Vale University Local Health Board.

\section{Results \\ Demographic results}

Of the 140 family members approached, seven declined to take part due to personal reasons such as shortage of time (response rate $95 \%$ ). One-hundred and thirty-three family members of patients with a wide range of mostly chronic conditions across 26 specialties were interviewed (Table 1). One-hundred and forty-four different medical conditions were represented in the study (Table 2), and $71 \%$ of patients suffered from more than one medical condition. Most family members were White British (93\%), female (61\%), the partner or spouse of the patient $(56 \%)$, or the parent $(22 \%)$ (Table 3$)$.

\section{Thematic analysis}

The mean number of themes mentioned by participants was six (median: 6, standard deviation: 2.03, range: 0-10 [maximum: 10]). Family members of hematology and genetics patients reported the most themes, and family members of gynecology and diabetes patients reported the lowest number of themes (Table 4).

The saturation point (calculated at the end of the 133 interviews) was reached at interview number 40, after which no new themes emerged. At least five participants were sampled 


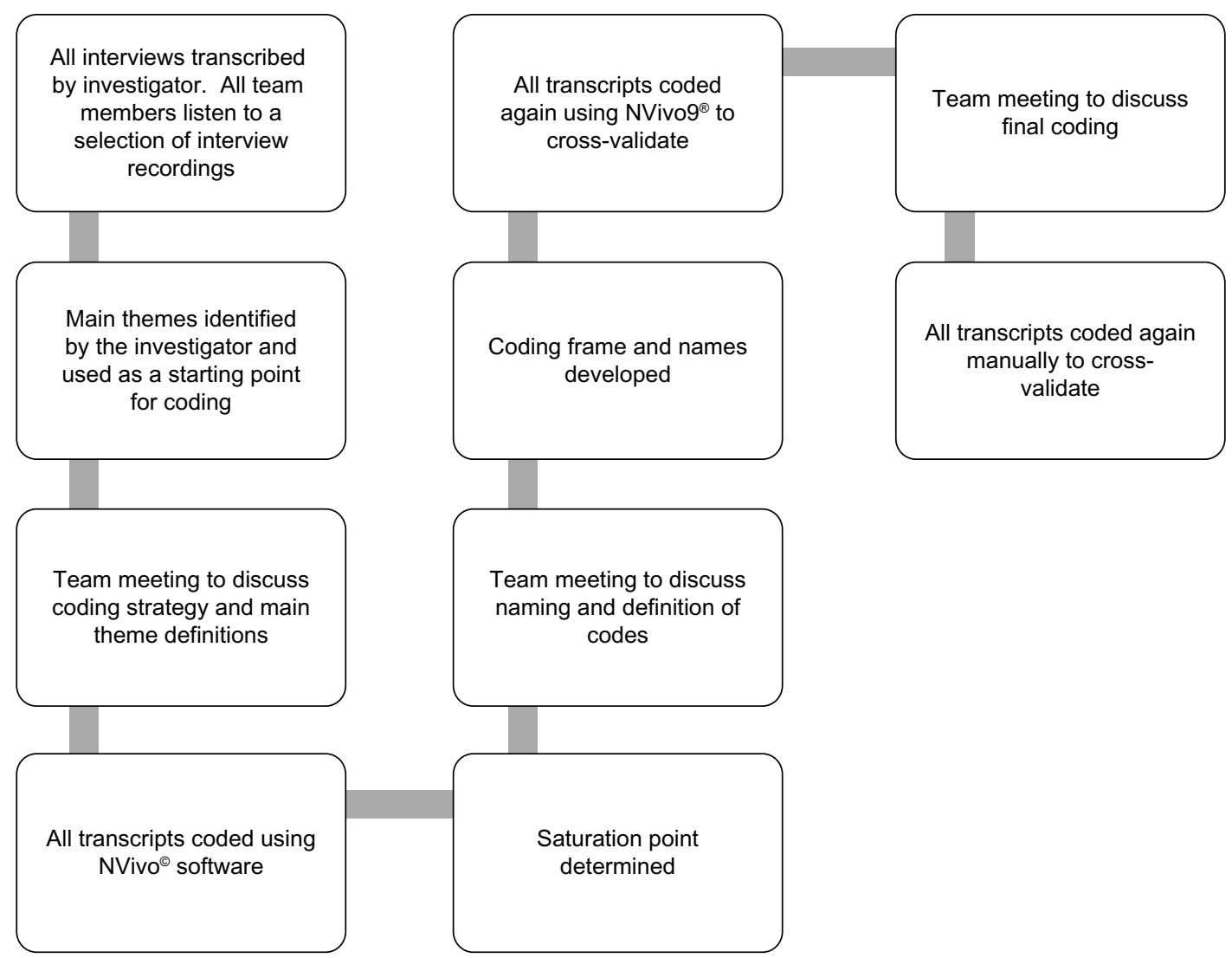

Figure I Flow diagram describing the analytical process.

Notes: NVivo9 ${ }^{\circledR}$ qualitative data analysis software (QRS international, Doncaster, Australia).

from each specialty apart from infectious diseases, general practice, and urology where six were selected. Between interview numbers 40 and 133, the participants gave different examples, adding to the richness of the data.

\section{Impact on quality of life}

Ten main themes were identified (Figure 2) and are discussed below. Although all the themes identified were interrelated, some themes were more closely linked. For example, financial impact was linked to holidays, and lack of ability to plan time impacted on social life. The "Emotional impact" theme was linked closely to most other themes, and family members reported that their emotional state affected most other areas of their lives.

\section{Emotional impact}

Ninety-two percent of the family members interviewed were affected emotionally by the patient's illness, mentioning worry (35\%), frustration (27\%), anger (15\%), and guilt $(14 \%)$. Worry was reported when the family members were thinking about the future or the patient's death. Less common psychological effects included feeling upset, annoyed, helpless, stressed, and lonely. Others relied on spiritual and religious input to deal with their emotions. Twenty percent of the family members found it difficult to find someone to talk to about these feelings. This often resulted in them bottling up their feelings and finding it very difficult to cope, with many describing breaking down in tears when alone. Several family members found themselves reflecting on what they had done to "deserve" having an unwell family member, developing a "why me?" attitude. One participant whose wife had been diagnosed with lymphoma explained:

You go through sort of like fear, anger the life that you had, you'll never have back because in the back of your mind there's always that worry of "Is it going to come back?"

\section{Daily activities}

The negative effect on day-to-day living as a result of having an unwell relative was reported by $91 \%$ of the family members. For 38\%, this involved aspects of caring, including helping with dressing, personal hygiene needs, assisting with mobility, and providing food. Many reported feeling a burden from caring for the patient, and feeling they had no freedom or time to enjoy their interests. Thirty-five percent reported their hobbies being affected. Forty-seven percent 
Table 2 The list of patient diagnoses in the study

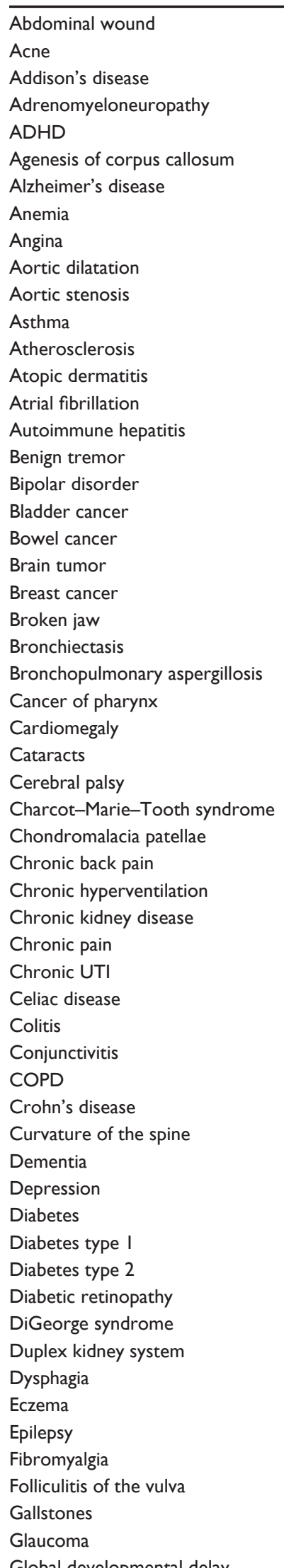

Global developmental delay
Table 2 (Continued)

GORD

Gout

Hemophilia

Hemophilic arthropathy

Hay fever

Hearing loss

Heart bypass

Heart failure

Hepatitis C

Hernia

HIV

Hypercholesterolemia

Hypertension

Hyperthyroidism

Hypothyroidism

Idiopathic pulmonary fibrosis

Incontinence

Irritable bowel syndrome

Ischemic heart disease

Ischemic nephropathy

Knee replacement

Large granular lymphocyte leukemia

Learning difficulties

Leber optic atrophy

Left ventricular failure

Leg ulcer

Leukemia

Lichen planus

Lichen sclerosis

Lupus

Lymphedema

Lymphoma

Macular degeneration

Microcephaly

Motor neuron disease

Multiple sclerosis

Muscular dystrophy

Myeloma

Neuromyelitis optica

Neuropathic pain

Non-Hodgkin's lymphoma

Obesity

Osteoarthritis

Osteonecrosis of the gums

Osteoporosis

Pancreatic transplant

Pancreatitis

Paralysis of vocal chords

Pituitary adenoma

Pneumonia

Polymyalgia rheumatica

Primary biliary cirrhosis

Prostate cancer

Pseudophakia

Psoriasis

Pulmonary embolism

Raynaud's phenomenon

Renal cancer

(Continued) 
Table 2 (Continued)

Retinal detachment

Rheumatoid arthritis

Rosacea

Sarcoidosis

Schizoaffective disorder

Schizophrenia

Sciatica

Sleep apnea

Small bowel cancer

Spinal surgery

Splenic lymphoma

Stomach ulcer

Stroke

Talipes

Talonavicular arthritis

Thyroid toxicosis

Trigeminal nerve damage

Turner syndrome

Upper Gl bleed

Urinary retention

Uterine cancer

Vascular disease

Vertigo

Visual inattention

Vulval intraepithelial neoplasia

Vulvodynia

Wart on gum

Wolff-Parkinson-White syndrome

Abbreviations: ADHD, attention deficit hyperactivity disorder; COPD, chronic obstructive pulmonary disease; GI, gastrointestinal; GORD, gastroesophageal reflux disease; HIV, human immunodeficiency virus; UTI, urinary tract infection.

increased the amount of housework they did. The daughter of an elderly patient with osteoporosis described:

I have reverted back to how it was when I was bringing up my children $[\ldots]$ to a certain extent $[\ldots]$ you are housebound [...]. Sometimes I get frustrated that I can't just go out like I once did.

\section{Family relationships}

Affected relationships among family members were reported by $69 \%$ of participants, with increased stress and tension. Twenty-six percent of family members felt that they had to be with the patient all the time to care for them, leading to them spending too much time with the patient instead of with other family members. This was especially true of patients' mothers who had other well children. Twenty-four percent of family members reported more family arguments. Partners and spouses found the role change to carer challenging, many reporting a negative effect on their sex life. Others reported a decline in their sexual relationship due to the patient's physical condition. A mother hated her diabetic
Table 3 Demographics of family members in the study $(n=133)$

\begin{tabular}{|c|c|c|}
\hline & $\mathbf{n}$ & $\%$ \\
\hline Total number of family members & 133 & \\
\hline Males & 52 & 39 \\
\hline Females & 81 & 61 \\
\hline Mean age of family members (years) & 56.1 & \\
\hline Interquartile range of ages of family & $44-69$ & \\
\hline members (years) & & \\
\hline \multicolumn{3}{|l|}{ Relationship to patient } \\
\hline Spouse/partner & 76 & 56 \\
\hline Parent & 29 & 22 \\
\hline Child & 20 & 15 \\
\hline Niece/nephew & 1 & I \\
\hline Grandparent & 2 & 2 \\
\hline Sibling & 2 & 2 \\
\hline Grandchild & 2 & I \\
\hline Cousin & I & I \\
\hline \multicolumn{3}{|l|}{ Educational level } \\
\hline Less than secondary school & 15 & II \\
\hline Secondary school & 45 & 34 \\
\hline A levels/college course & 36 & 27 \\
\hline University degree & 22 & 17 \\
\hline Masters/doctoral degree & 8 & 6 \\
\hline Prefer not to say & 2 & 2 \\
\hline Missing data & 5 & 3 \\
\hline \multicolumn{3}{|l|}{ Ethnicity } \\
\hline White British & 124 & 93 \\
\hline Mixed & 2 & 2 \\
\hline Asian or Asian British & 4 & 3 \\
\hline Black or Black British & 3 & 2 \\
\hline \multicolumn{3}{|l|}{ Combined annual household income } \\
\hline Less than $£ 10,000$ & 17 & 13 \\
\hline$£ 11,000-£ 20,000$ & 34 & 26 \\
\hline$£ 21,000-£ 30,000$ & 30 & 23 \\
\hline$£ 31,000-£ 40,000$ & 10 & 7 \\
\hline$£ 41,000-£ 50,000$ & 8 & 6 \\
\hline$£ 51,000-£ 60,000$ & 6 & 4 \\
\hline$£ 61,000-£ 70,000$ & 5 & 3 \\
\hline$£ 71,000-£ 80,000$ & 1 & I \\
\hline$£ 81,000-£ 90,000$ & 2 & 2 \\
\hline$£ 91,000-£ 100,000$ & 0 & 0 \\
\hline Over $€ 100,000$ & I & $\mathrm{I}$ \\
\hline Prefer not to say & 12 & 9 \\
\hline Missing data & 7 & 5 \\
\hline Mean age of patients (years) & 54.7 & \\
\hline Interquartile range of ages of patients (years) & $35-76$ & \\
\hline Mean duration of patient's disease (years) & 8.9 & \\
\hline $\begin{array}{l}\text { Interquartile range of duration of patient's } \\
\text { disease (months) }\end{array}$ & $|2-| 4 \mid$ & \\
\hline
\end{tabular}

teenage daughter because of the way her illness had affected the family, sometimes wishing her dead. Another said his mother's illness caused his marriage breakdown.

\section{Sleep and health}

Sixty-seven percent of participants reported a negative impact on their sleep and health. Sleep loss was caused by worry (32\%) 
Table 4 The mean and median number of themes mentioned by family member of patients in each specialty (arranged by decreasing mean)

\begin{tabular}{lll}
\hline Specialty & $\begin{array}{l}\text { Mean number } \\
\text { of themes } \\
\text { mentioned by } \\
\text { family members }\end{array}$ & $\begin{array}{l}\text { Median number } \\
\text { of themes } \\
\text { mentioned by } \\
\text { family members }\end{array}$ \\
\hline Hematology & 8 & 9 \\
Neurology & 8 & 8 \\
Genetics & 7 & 9 \\
General practice & 7 & 8 \\
Oncology & 7 & 7 \\
Cardiology & 7 & 7 \\
Mental health & 7 & 6 \\
Colorectal surgery & 6 & 6 \\
Pediatric endocrinology & 6 & 7 \\
Elderly & 6 & 7 \\
Orthopedics & 6 & 6 \\
Rheumatology & 6 & 6 \\
Gastroenterology & 6 & 7 \\
Renal & 6 & 6 \\
Urology & 6 & 6 \\
Chronic pain & 6 & 6 \\
Ears, nose, and throat & 6 & 6 \\
Respiratory & 6 & 6 \\
Infectious diseases & 5 & 5 \\
Dental surgery & 5 & 5 \\
Dermatology & 5 & 6 \\
Post-stroke & 5 & 6 \\
Wound healing & 5 & 5 \\
Gynecology & 5 & 4 \\
Ophthalmology & 4 & 3 \\
Diabetes & 4 & \\
\hline
\end{tabular}

and by having to wake to help the patient (38\%) for personal hygiene needs or medication. Another reason for sleep loss was feeling the need to wake to check the patient was still alive. Some participants described a decline in their own health: several developed depression. The mother of a teenager with schizoaffective disorder described:

I was living off $[\ldots] 2$ or 3 hours sleep a night and this was [...] for 18 months and in the end [...] even antidepressants don't help $[\ldots]$ just total anxiety all the time.

\section{Holidays}

Problems associated with going on holiday were reported by $62 \%$ of family members. The most common was not being able to go on holiday at all (31\%) because the patient was too unwell, because of hospital appointments, or worrying about food abroad. The mother of a child with a duplex kidney described:

Getting on a plane where you know your child will disturb other passengers and where she needs the toilet lots $[\ldots]$ up and down the alleyway [...] it's that embarrassment and fear.

\section{Involvement in medical care and support given to family members}

Sixty-one percent of the family members described lack of support from friends and other family members. They often felt others did not understand what they were going through

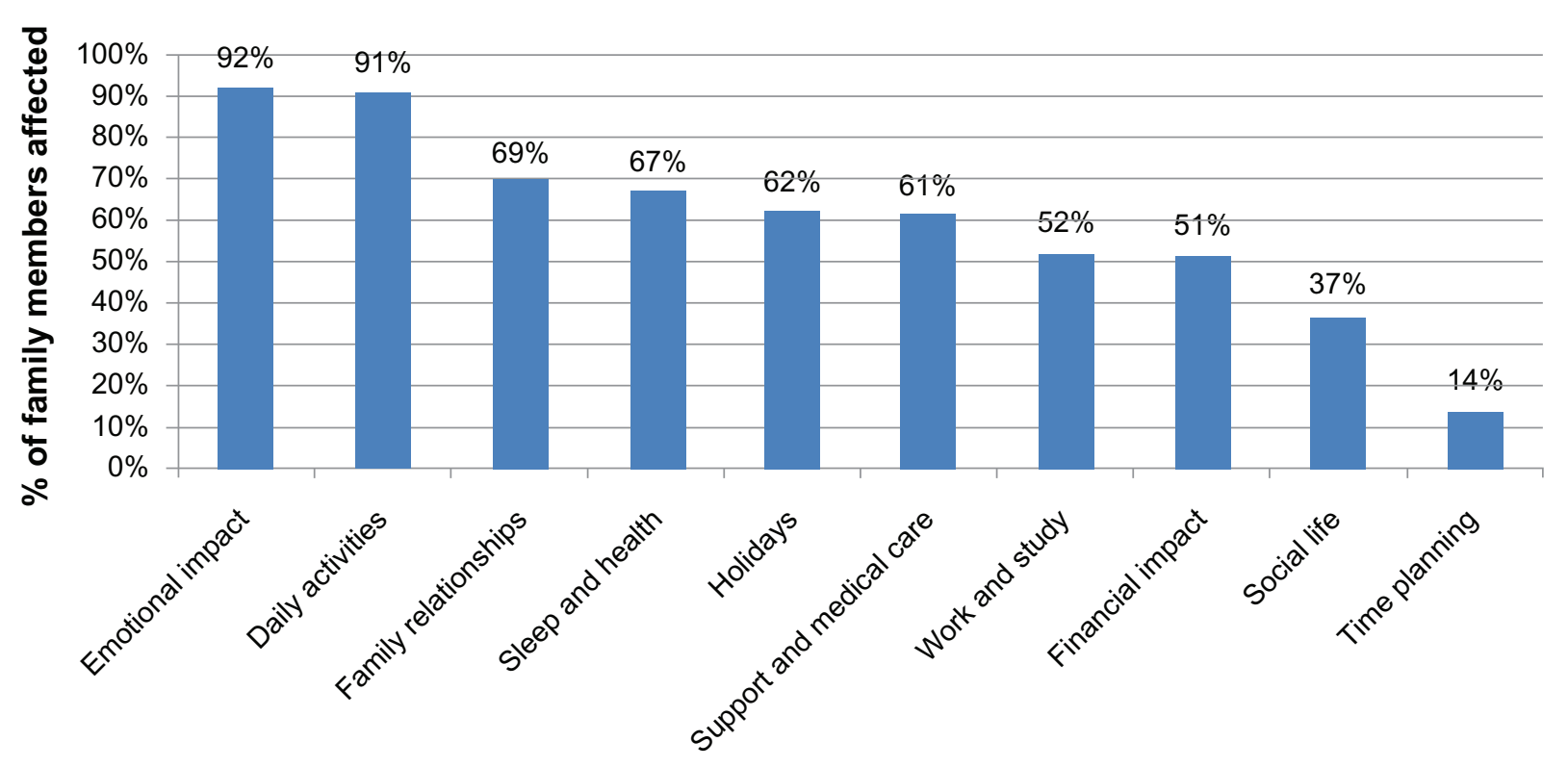

Theme

Figure $\mathbf{2}$ The ten themes identified in the study and the percentage of family members affected by each. 
and many found it difficult to talk about the patient's illness, through embarrassment or lack of knowledge. Family members needed to remind patients to take medication. Several described being affected by the timing of hospital appointments and not being given enough information about the patient's condition. One family member, whose mother had angina, described:

Half the time people don't want to know [...] I've got [...] brothers and sisters and none of them visit. You feel that they are selfish and they load it all on you.

A few of the family members also talked about how support groups and meeting other family members in similar situations would help them to cope with the impact of the patient's illness. No family members reported having either sought or having received help from professionals such as psychologists or doctors concerning the impact of having a family member with a chronic disease.

\section{Work and study}

Fifty-two percent of the family members described how their own work or study was affected. Participants had to take time off work to look after the patient or attend their medical appointments. This caused difficulties with colleagues, and in $9 \%$ of cases the family member gave up their job completely. This had a huge financial impact on the families. The husband of a patient with severe depression said:

I just didn't have the time [to work]. There are so many appointments to go to and obviously my wife needed care, it got very difficult to carry on [with work].

\section{Financial impact}

The financial impact of disease on the family (reported by $51 \%$ ) was great. Twenty-six percent reported having to spend money relating to the patient's illness. Areas of financial impact included mobility aids, clothes, transport, holiday insurance, private health care, and the huge impact of the patient or family member giving up work. One family member said:

I gave up a job with very good salary and my husband gave up full time work [...] my parents help us out a lot with money. We couldn't survive without $[\ldots]$.

\section{Social life}

Thirty-seven percent of family members reported impacts on their social life (interactions with people, activities, and places) because of lack of money or needing to leave social events early. Eight percent were concerned how strangers would react to their relative's medical condition - especially when visible, eg, skin disease. The wife of a patient with multiple myeloma described:

$[\ldots]$ we used to go out $[\ldots]$ but now we can't do it because with the treatment he doesn't eat properly so [...] why pay all that money if he's not going to eat it [...] and he's lost [...] weight so we don't want people to see him.

\section{Time planning}

Fourteen percent of the participants talked about difficulty in being able to plan their time because of attending medical appointments at short notice and the unpredictability of patients' symptoms. Family members also talked about not being able to plan activities in advance, such as holidays and family activities, and complained that they had lost "spontaneity" and "freedom" in their lives. One family member said:

I get really frustrated and a bit angry, it's very unfair of me but I don't seem to be able to plan anything anymore. You know, if someone says "Would you like to come?" and I say "I'll let you know", because I know damn well that I'll probably have to let them down if I say I'm going.

\section{Positive effects}

As well as the negative effects, a small number of positive effects were also identified by family members during the interviews. Thirteen percent of the family member's interviews managed to identify one positive effect of the patient's illness on their life, and these positive effects were only identified under the "Emotional impact" and "Family relationships" themes. In these positive examples, family members described relationships within the family improving as a result of the patient's illness, with members of the family pulling together to support each other. One family member said:

I suppose it's making our relationship stronger "cause it's making us work through things."

Other family members described overcoming the personal "challenge" of the patient's illness and making them realize how precious their own life is.

\section{Discussion}

The impact of a patients' illness on families is widespread and profound. Family members are affected in multiple ways 
across all medical specialties. This study has identified the major ways in which family lives can be affected by disease and the commonality of issues across all diseases. This is the first study to identify the similar experiences of family members of patients across the whole of medicine, and the unique findings are relevant to all health care professionals, because all health care professionals who interact directly with patients, whether they realize it or not, are impacting on a close social network involving the family members of each patient. The effect of individual patients' disease on the quality of life of their family members may have major implications on the quality of care and concordance with treatment that the patient receives. In addition, the health care worker arguably may have some responsibility for understanding the impact that the patient's condition is having on their family members, and may be in an ideal position to advise the family member how to seek appropriate support. Even in those specialties where family members are least affected, they still reported being affected by three of the ten themes, demonstrating that the family impact of disease needs to be considered and addressed in all areas of medicine. Over one-third of the family members reported having to provide care to the patient, although they were not asked whether they were the primary caregiver. Whether or not the patients required family members to provide care, the lives of the family members may still have been affected. Many participants said how grateful they were to talk about the subject, that they had never been asked about it before, and voiced the lack of support they had received in dealing with the effects of the patient's illness.

Family members of patients from all specialties felt a great emotional impact, the most widely previously reported topic. ${ }^{12}$ They often felt they had to hide their feelings from the patient in order to provide support - for many this was very difficult. This emotional impact has a major influence on many areas of their lives, eg, on health ${ }^{13,14}$ and sleep. Family members of patients can be more emotionally affected than the patients themselves, particularly in the area of oncology. ${ }^{15}$ This may be because attention is mainly focused on the patient and much consideration given to the patient's needs. In contrast, the family member and their concerns are usually ignored or not understood.

The impact of illness on family relationships was extensively described by participants. Optimal chronic disease management depends on good family relationships, but often family members do not know how to emotionally support each other. ${ }^{16}$ Partners of patients described the negative impact that the patient's condition can have on their sex life. ${ }^{1,17-19}$ The difficulties faced due to the changing role of the family member in the patient's life have also been reported in a previous study with family members of patients with multiple sclerosis. ${ }^{20}$

The impact on family finances and employment were major issues. Family members described the financial impact of having to reduce or give up work as a result of the patient's illness, often compounded by the patient also giving up work. Looking after an unwell patient is expensive. ${ }^{21-23}$ If the $9 \%$ of the family members in this study who gave up work was representative, this represents many potentially unemployed. Family members claim carer benefits as they find it difficult to access alternative funding. ${ }^{24,25}$ With adequate social support some of these family members might have been able to continue working. Many of the financial issues reported by family members in this study were similar to those found in a previous study with family members of children with chronic disease, ${ }^{26}$ including reporting the increased cost of food items and employment problems.

Family members described their own existing medical conditions worsening and several developed depression. This study identifies family members as a hidden "patient" group, with an apparent "ripple effect" of illness; one patient being unwell has the potential to create several more "patients" in the family. ${ }^{27}$ This can then magnify problems with finances and family relationships, in a vicious cycle. This hidden burden has a potentially huge financial impact on the health care system that could potentially be reduced by appropriate family support.

Patients suffering from more than one medical condition were not excluded from the study as it was felt that including patients with comorbidities would more closely reflect reality. The interviewer found it easy to focus the participant on the effects of the principal diagnosis - any extra information added to the richness and variety of the data.

Although this study focuses on the negative impact on family members' lives, many participants also described positive effects. Some family members felt closer to the patient through supporting each other in difficult times, and others described making more effort to spend time as a family. ${ }^{21}$ However, these positive effects did not outweigh the huge burdens felt by family members, and many could not identify any positive effects.

Several major areas have been identified where further support is needed for family members. Clinicians should assess the potential impact of decisions on the patient's family, thinking of the ten main themes identified. For example, 
which treatment course would cause a greater burden to family members? Could a patient's low mood be the result of strained family relationships due to their disease? Does the patient's family need a financial support assessment? With the patient's consent, the clinician should ideally involve the family in discussions about management. ${ }^{1}$ Support services for family members should be established to address their problems, ideally with family members themselves identifying and evaluating the services required. ${ }^{28}$ This study provides evidence for the need for support, particularly emotional support - the area in which family members are affected to the greatest extent. Family support groups for patients with a variety of diseases might be effective as the ways that families are affected are similar across the whole of medicine. Such support might ease the emotional impact on family members, protect their health, and improve family relationships. The results of this study could be used in clinical consultations and to aid the design of family support services and educational programs.

There were limitations to this study. The majority of participants were White British. It is possible that culture and ethnicity could influence the way family members are affected by illness, and some themes could be of greater importance to specific cultural groups. This could be determined by further sampling family members of patients from different ethnic backgrounds. Another limitation is that the range of medical conditions from each specialty was not represented fully. However, physicians were asked to select patients with different conditions best representing their specialty. This expert knowledge and the large total number of interviews carried out beyond the saturation point helped to ensure a representative sample. This study did not consider whether the effects on different family members are similar; this could be addressed in the future by interviewing more than one family member of each patient.

The coding was carried out by one individual: although using only one coder could be considered a significant limitation, there was regular and active involvement of the other members of the study team during all stages of the coding. Although one individual named the themes (this individual carried out the interviews and so had the greatest understanding of the interview content and played a leading role), the team then met to discuss the naming and definitions of the themes and how they would be interpreted during the coding. In addition, extra efforts were put into place to reduce coder bias: team members listened to a selection of interview recordings, the team met regularly to discuss the naming and definitions of the themes and codes in great detail, and coding was cross-validated manually and using NVivo software.
Sample selection could have introduced some bias. For example, relatives of perceived more compliant patients may have been selected in preference to distressed patients. However, the 26 different recruiting times were likely to have different biases, which may have mitigated against this. In addition, saturation was reached at interview number 40; the rest of the 93 interviews revealed no new themes. Therefore, it is most unlikely that any themes were missed even if there were selection biases. The huge range of different specialties and diseases covered also makes any impact of selection bias much smaller.

The results of this study could be used to inform the development of a larger scale study to draw direct comparisons between the impact of illness on family members across different specialties or different groups of family members. Future studies could determine whether these results are applicable to family members across different cultures. The possibility that unique themes such as dealing with possible death of the patient may be relevant to family members of specific disease populations could be assessed in future disease-specific studies. Although the key areas of family quality of life have been identified by this study, there is still no established method to measure these for research purposes or for families in clinical settings. The development of a generic family quality of life measure would allow the appropriate assessment of the effect of interventions designed to improve family quality of life.

\section{Conclusion}

This multi-specialty study has demonstrated the huge, yet similar, impacts that illness can have on the quality of life of family members of patients. Family quality of life is a previously neglected critical area of health care that needs to be addressed by all health care professionals in order to provide appropriate support for both patients and family members.

\section{Acknowledgments}

The authors wish to acknowledge the following specialists who helped with data collection in this study: Dr Shakeel Ahmad, Dr Maria Atkins, Professor Angus Clarke, Dr Annabel Borley, Dr Gwilym Bowen, Dr Adeline Cutinha, Mrs Wendy Davies, Dr Andrew Freedman, Dr Lindsay George, Dr John Green, Professor John Gregory, Professor Julian Halcox, Dr Ben Hope-Gill, Dr Sharon Jones, Mr Hrishi Joshi, Dr Manju Kalavala, Dr Sharmila Khot, Professor Malcolm Mason, Mr Philip Matthews, Dr Richard Moore, Professor James Morgan, Ms Elizabeth Mudge, Mr Declan O'Doherty, Professor Neil Robertson, Dr Clare Rowntree, Dr Caroline 
Scherf, Professor Jonathan Shepherd, Dr Victor Sim, Dr John Staffurth, Mr Alun Tomkinson, Mr Jared Torkington, and Dr Amanda Tristram. The authors wish to thank the patients and family members who took part in the study. They also wish to thank the consultants, nurses, administrative staff, and clinic coordinators at the Cardiff and Vale University Health Board who were involved in facilitating the study.

\section{Disclosure}

AYF, MKAB, and Cardiff University are joint copyright owners of the Family Dermatology Life Quality Index. The other authors report no conflicts of interest in this work.

\section{References}

1. Basra MKA, Finlay AY. The family impact of skin diseases: the Greater Patient concept. Br J Dermatol. 2007;156(5):929-937.

2. Guyatt GH, Feeny DH, Patrick DL. Measuring health-related quality of life. Ann Intern Med. 1993;118(8):622-629.

3. Poston D, Turnbull A, Park J, Mannan H, Marquis J, Wang M. Family quality of life: a qualitative inquiry. Ment Retard. 2003;41(5):313-328.

4. Swanberg JE. Making it work: informal caregiving, cancer, and employment. J Psychosoc Oncol. 2006;24(3):1-18.

5. Kornblith AB, Herr HW, Ofman US, Scher HI, Holland JC. Quality of life of patients with prostate cancer and their spouses. The value of a data base in clinical care. Cancer. 1994;73(11):2791-2802.

6. Weitzenkamp DA, Gerhart KA, Charlifue SW, Whiteneck GG, Savic G. Spouses of spinal cord injury survivors: the added impact of caregiving. Arch Phys Med Rehabil. 1997;78(8):822-827.

7. Youngblood NM, Hines J. The influence of the family's perception of disability on rehabilitation outcomes. Rehabil Nurs. 1992;17(6): 323-326.

8. Bryman A. Social Research Methods. Oxford: Oxford University Press; 2001.

9. Kerr C, Nixon A, Wild D. Assessing and demonstrating data saturation in qualitative inquiry supporting patient-reported outcomes research. Expert Rev Pharmacoecon Outcomes Res. 2010;10(3):269-281.

10. Braun V, Clarke V. Using thematic analysis in psychology. Qual Res Psychol. 2006;3(2):77-101.

11. Gabriel Z, Bowling A. Quality of life from the perspectives of older people. Ageing Soc. 2004;24(5):675-691.
12. Bowen C, MacLehose A, Beaumont JG. Advanced multiple sclerosis and the psychosocial impact on families. Psychol Health. 2011;26(1): 113-127.

13. Osse BH, Vernooij-Dassen MJ, Schade E, Grol RP. Problems experienced by the informal caregivers of cancer patients and their needs for support. Cancer Nurs. 2006;29(5):378-388.

14. Demi A, Bakeman R, Moneyham L, Sowell R, Seals B. Effects of resources and stressors on burden and depression of family members who provide care to an HIV-infected woman. J Fam Psychol. 1997; 11(1):35-48.

15. Hagedoorn M, Buunk BP, Kuijer RG, Wobbes T, Sanderman R. Couples dealing with cancer: role and gender differences regarding psychological distress and quality of life. Psychooncology. 2000;9(3):232-242.

16. Lewis FM. Strengthening family supports: cancer and the family. Cancer. 1990;65(Suppl 3):752-759.

17. Rolland JS. In sickness and in health: the impact of illness on couples' relationships. J Marital Fam Ther. 1994;20(4):327-347.

18. Eghlileb AM, Davies EE, Finlay AY. Psoriasis has a major secondary impact on the lives of family members and partners. Brit J Dermatol. 2007;156(6):1245-1250.

19. Elliott BE, Luker K. The experiences of mothers caring for a child with severe atopic eczema. J Clin Nurs. 1997;6(3):241-247.

20. Boeije HR, Van Doorne-Huiskes A. Fulfilling a sense of duty: how men and women giving care to spouses with multiple sclerosis interpret this role. Community Work Fam. 2003;6(3):223-244.

21. Brown I, Anand S, Fung WLA, Isaacs B, Baum N. Family quality of life: Canadian results from an international study. J Dev Phys Disabil. 2003;15(3):207-230.

22. Langa KM, Chernew ME, Kabeto MU, et al. National estimates of the quantity and cost of informal caregiving for the elderly with dementia. J Gen Intern Med. 2001;16(11):770-778.

23. Clarke SA, Skinner R, Guest J, et al. Health-related quality of life and financial impact of caring for a child with thalassaemia major in the UK. Child Care Health Dev. 2010;36(1):118-122.

24. Davis E, Shelly A, Waters E, et al. The impact of caring for a child with cerebral palsy: quality of life for mothers and fathers. Child Care Health Dev. 2010;36(1):63-71.

25. Lapidus CS, Kerr PE. Social impact of atopic dermatitis. Med Health R I. 2001;84(9):294-295.

26. Gannoni AF, Shute RH. Parental and child perspectives on adaptation to childhood chronic illness: a qualitative study. Clin Child Psychol Psychiatry. 2010;15(1):39-53.

27. Lieberman MA, Fisher L. The impact of chronic illness on the health and well-being of family members. Gerontologist. 1995;35(1):94-102.

28. Given BA, Given CW, Kozachik S. Family support in advanced cancer. CA Cancer J Clin. 2001;51(4):213-231. 


\section{Supplementary material}

A summary of the interview guide used

\section{Introduction}

- Remind participant that the information they give is confidential.

- Remind participant that the interview will be tape recorded.

- Remind participant that they can terminate the interview at any time.

- Tell the participant that the purpose of the interview is to find out how their lives have been affected by having a relative with a disease, and encourage them to answer questions as honestly as they can, giving examples when possible.

\section{Opening question}

- Can you tell me about any ways your life has been affected by your family member's condition?

\section{Main interview questions (overview)}

- Can you tell me how living with someone with your relative's condition makes you feel?

- Can you tell me what things in particular make you feel like this? Can you give examples?

- Do your activities change as a result of feeling like this? If so, how?

- How do you cope with feeling like this?

- Who do you talk to about feeling like this?

- Do you use any support services e.g. websites/counseling to help you with your feelings? If so, what do you use and why?

- How does your relative's condition affect your social life?

- Can you think of any social activities that you used to do which you can't now as a result of your relative's condition?
- What effect does your relative's condition have on your day to day activities?

- Does your relative's condition have any effect on your housework? If so, how?

- What effect does your relative's condition have on your friendships with others, both friends and strangers?

- Has your relative's condition affected any relationships in your family? If so, how?

- Do you feel that any of the family member's roles or responsibilities have changed as a result of your relatives condition? Can you explain how?

- Do you buy anything special of different as a result of your relative's condition? Can you explain what and why?

- Do you have any financial problems associated with your relative's condition? What are the cause of these?

- Does your relative's condition affect your job at all? If so, how?

- Has your relative's condition affected going on holiday at all? If so, how?

- Does your relative's condition affect your sleep? If so, why?

- Has your relative's condition affected your health at all? If so, how?

- Have you changed what you eat at all? If so, how?

- Do you have any support from people or groups? Can you tell me more?

- Has your sex life been affected at all? (partners only) If so, how?

\section{Closure}

- Is there anything else you can think of that you haven't told me?

- Is there anything else you would like to discuss?

- Thank you for your time

\section{Publish your work in this journal}

The International Journal of General Medicine is an international, peer-reviewed open-access journal that focuses on general and internal medicine, pathogenesis, epidemiology, diagnosis, monitoring and treatment protocols. The journal is characterized by the rapid reporting of reviews, original research and clinical studies across all disease areas.
A key focus is the elucidation of disease processes and management protocols resulting in improved outcomes for the patient.The manuscript management system is completely online and includes a very quick and fair peer-review system. Visit http://www.dovepress.com/ testimonials.php to read real quotes from published authors. 